\title{
Being old and living alone in urban areas: the meaning of self-care and health on the perception of life situation and identity
}

This article was published in the following Dove Press journal:

Psychology Research and Behavior Management

17 June 2013

Number of times this article has been viewed

\author{
Kari Sundsli ${ }^{1,2}$ \\ Geir Arild Espnes ${ }^{3}$ \\ Olle Söderhamn² \\ 'Department of Social Work and \\ Health Science, Norwegian University \\ of Science and Technology, Trondheim, \\ ${ }^{2}$ Centre for Caring Research - \\ Southern Norway, Faculty of Health \\ and Sport Sciences, University of \\ Agder, Grimstad, Norway; ${ }^{3}$ Research \\ Centre for Health Promotion and \\ Resources, Norwegian University of \\ Science and Technology, Trondheim, \\ Norway
}

Background: Living alone in urban areas when getting old is an important and necessary field for research as the growth of the urban population worldwide increases, and due to the fact that people live longer. How older people manage their self-care and health, and how this might influence their identity and life situation may be very important to understand when planning for a new, upcoming older generation. The aim of this study was to elucidate the meaning of self-care and health for the perception of life situation and identity among single-living older individuals in urban areas in southern Norway.

Methods: A phenomenological-hermeneutic approach inspired by Ricoeur was applied. Nine single-living older persons in urban areas, 70-82 years of age, and identified to be in good health were interviewed. The interviews were audiotaped, transcribed verbatim, and analyzed using a phenomenological-hermeneutic method.

Results: Strength and a time dimension characterized the meaning of self-care and health for the perception of life situation and identity as narrated by the group of single-living older individuals in urban areas in southern Norway. The informants were, as older individuals, caring, autonomous, and robust characters, who had gone through difficult times in life, and in a resilient way moved towards a new future. They valued and were grateful for what they had learned in their lives and could go forward and still experience and explore.

Conclusion: Self-care is significant in the perception of life situation and identity among single urban older people in this study, and characterized by strength, temporality, gratitude, autonomy, and natality. Society needs to acknowledge the strengths and capabilities of older people to a greater extent.

Keywords: aged, health promotion, phenomenological-hermeneutic method, salutogenesis, time

\section{Introduction}

Urban areas have an important impact on older peoples' life situation and identity. The growth in urban population worldwide will in the next few decades occur in small and midsize cities, and for developing countries there will be $40 \%$ growth by 2030 in these cities. ${ }^{1}$ Despite urbanization and the aging population, and the fact that health outcomes are better in cities in wealthy countries than those in low-income countries, ${ }^{2}$ urban life seems to be a good life on the whole. ${ }^{3,4}$ Health inequalities, social inequalities, and the diversity in cities are factors that need to be embraced when urban health is the issue. ${ }^{2}$ Taking this into account, various studies ${ }^{2,5,6}$ have shown more satisfaction with aging, higher self-esteem, increased positive mood, better emotional health, better functional health status, and a higher degree of physical function and mental health than their counterparts living in rural areas.
Centre for Caring Research - Southern Norway, Faculty of Health and Sport Sciences, University of Agder, PO Box 509, 4898 Grimstad, Norway Tel +4737233784

Email kari.sundsli@uia.no 
Living alone in urban areas should to some extent be a well-known and documented area of research internationally. There is, however, little research involving single-living older people and the meaning of self-care and health in urban areas. A descriptive study on the life satisfaction of older Europeans living alone found that the most important thing for life satisfaction was no health limitations. ${ }^{7}$ Other major determinants were high levels of education and incomes. ${ }^{7}$ In a qualitative phenomenological-hermeneutic study from Norway, self-care and health among older single-living people in rural areas were elucidated, and their life situation was interpreted as inevitable, appropriate, and meaningful. ${ }^{8}$ Further studies have shown that living alone might be a risk factor for undernutrition, depression, and loneliness among older people. ${ }^{9,10}$ While this is the negative side of the coin, older people living alone reveal themselves as being independent, having control, and having a positive and proactive attitude. ${ }^{11,12}$

Self-care might be viewed as acts an individual initiates and performs on his or her own behalf in maintaining life, health, and well-being. Orem ${ }^{13}$ claims in her self-care deficit theory that deficit in this context should be interpreted as a relationship, not as a human disorder. The relationship should be understood as the relationship between the capabilities of individuals and their demands for self-care. One central phenomenon in the concept of self-care is self-care agency, which consists of self-care ability and activity. Self-care ability may be conceptualized as potentiality and a necessary condition for self-care activities. ${ }^{14}$

Identity is closely connected to the integrity of the individual's body and mind, and may also be dependent on the subject's self-image. ${ }^{15}$ Answering the question "Who am I?" as well as such questions as "Who do I want to be?" and "What gives meaning to my life?" might be the best way to describe the question of identity, and the answer will be an understanding of what is of crucial importance to us. ${ }^{16}$ Our identity is defined by the commitments and identifications that provide the frame in which we can try to determine case by case. Such cases might be questions of what is good or valuable, or what ought to be done, or what do we endorse or oppose.${ }^{16}$ The identity is not developed by the self in solitude; rather, it is developed through dialogues in relationships with other human beings. ${ }^{17}$ Models of self-exploration that have shaped modern culture can be traced through a line back to Augustine. His inward turn, for the sake of seeking God, was of great influence in the West, which in later time took on secularized forms. Modern people go inward, but not necessarily to find God. They go inward to discover or expose some order, or some meaning or some justification, to their lives. Developing one's identity seems to be an ongoing process during the life span, and not a fixed condition obtained in early adulthood. ${ }^{18}$

There is a need for qualitative studies in the field of self-care research, with special regard to single-living older people, for obtaining a deeper understanding of the phenomenon of self-care and health, and how this might influence older people's identity and life situation.

The aim of this study was to elucidate the meaning of self-care and health for the perception of life situation and identity among single-living older individuals in urban areas in southern Norway.

\section{Methods \\ Design}

In this study, a phenomenological-hermeneutic method developed by Lindseth and Norberg ${ }^{19}$ and inspired by Ricoeur's interpretation theory ${ }^{20}$ was applied. This method ${ }^{19}$ has been developed for interpreting interview texts, trying to obtain a deeper understanding of the experience of the phenomenon in focus, which in this study was the meaning of self-care and health for the perception of life situation and identity among single-living older individuals in urban areas. Ricoeur tries to impart a hermeneutic epistemology when presenting three problem areas - the text, the act, and the history - and where the same question concerning the methodological dualism between explaining and understanding is posed, and where one does not rule out the other. Instead, it is two subsequent elements in one complicated process, which he calls interpretation. It seems that Ricoeur wants to fix the discourse, or that which happens between the explanation and the understanding, to grasp the plot or the phenomenon. To grasp this phenomenon, to understand, is not just to repeat the speech or text in a similar event: it is to generate a new event beginning from the text in which the initial event has been described. It is to reconstruct the whole into parts, as it is in construing the details that we construe the whole. ${ }^{20}$ The phenomenological-hermeneutic method inspired by Ricoeur implies that the discourse of human beings can be fixed as texts. It consists of three steps: naïve understanding, structural analysis, and interpreted whole. The first step provides a naïve grasp of the text as a whole. The structural analysis aims at an understanding of the phenomenon, and in the interpreted whole both the naïve understanding and the structural analysis are taken into account. ${ }^{19,20}$ The method has been used in other studies concerning health, well-being, and nursing. ${ }^{8,21-23}$ 


\section{Study group}

The participants were all part of a larger study on self-care and health among older home-dwelling people in urban areas in southern Norway, ${ }^{4}$ which included 1044 persons. For the current study the inclusion criteria were $\geq 65$ years of age, living alone, and perceiving oneself in good health. From a sample of 296 persons who fulfilled the inclusion criteria, 40 people were randomized and invited to participate in the study. After two reminders, nine persons had signed and returned the written consent for participation. The study group consisted of eight women and one man. Four of the participants lived in their own houses and three in their own apartments, while one lived in an assisted-living apartment. Four of the women were widows and four were divorced, while the man was a widower.

\section{Interviews}

When informed consent was received, the participants were contacted via telephone by the first author and appointments were arranged. All interviews took place in the participants' homes during the period December 2010 to June 2011, were audiotaped, and lasted 40-90 minutes. The following request was posed initially: "Please tell me about a situation where you experienced well-being by doing things by yourself, for yourself, in order to maintain health.” During the interview, the interviewer checked her understanding of the narrative or elements in the narrative with the interviewees and used such questions as "What do you mean?" or "Could you tell me more about ... ?" The narrated interviews were transcribed verbatim, with pauses, particles, and laughs included in the text, which might be important for the content of the text and for the research aim. ${ }^{19}$ The person's situation and the context in which the informant and the interviewer were situated was considered. ${ }^{19}$

\section{Analyses}

All interviews were analyzed, in accordance with Lindseth and Norberg, ${ }^{19}$ by the first author in close communication with the last author, who critically read through all the steps in the analyses. The final results were interpreted and formulated in close cooperation between the authors. The authors have backgrounds as registered nurses and researchers in the fields of self-care and health among older people.

Each transcribed interview was read with a natural attitude, ie, taking life for granted, trying to grasp the texts' meaning as a whole. Doing this, we were touched and moved as we allowed the text to speak to us. The naïve understanding of the text was written in a phenomenological language as a first imagination, to be validated or invalidated by the structural analysis. The presented naive understanding was the last obtained naïve understanding of the texts.

The structural analysis was performed when each interview was read as a whole and divided into meaning units. Each meaning unit was a piece of any length that brought forth just one meaning. The meaning units were read several times and reflected on against the naïve understanding and condensed into everyday words as precisely as possible. All the condensed meaning units were read through for similarities as well as differences, and all similar units were categorized into subthemes and themes. Finally, all the interview texts were interpreted as a whole, where naïve understanding and structural analysis were both taken into account.

\section{Ethics}

The study was approved by the Regional Committee for Medical Research Ethics. The participants were informed about the study by a written paper in addition to the written informed consent, and they were guaranteed anonymity and confidentiality according to the Declaration of Helsinki ${ }^{24}$ and common principles used in clinical research. ${ }^{24,25}$

\section{Results Naïve understanding}

Experiences of self-care and health in a context of living alone were narrated with a good-humored attitude and "taking things as they come." The informants emerged as independent, generous, and forward-looking, as well as remembering older days. They appreciated every day with its joys and sorrows, were grateful for family and friends, and anticipated public help if needed.

\section{Structural analysis}

\section{Remembering}

Looking back, remembering earlier days

The participants were looking back in life, remembering their childhood, their youth, and their early adulthood, remembering working hard at home as well as going to school, where they often had to walk long distances to get there. Some of them remembered the joy they felt when, for example, their birthday was coming up. Many of them remembered important things that they had been told as a child and that they had valued in their adult life and still did. The participants revealed their thoughts and feelings of going through one or more breakdowns of relationships; regardless of this, they found their lives today good or even better. 


\section{Being grateful}

Appreciating the day, being grateful for friends and family, and life situation

Being grateful and appreciating the day were expressions of great importance for the participants in order to picture their life situation. Although most participants had children and close families, they very much emphasized social activities and fellowship in which they took part, and which had an important impact on their health and life situation. They expressed their engagement in keeping up with the times according to rapid development regarding technology. Furthermore, they underlined their excitement for life: that there is still a lot to experience and explore; therefore, they hoped to live a long life.

\section{Being forward-looking} Living through change

All of the participants had lived parts of their lives together with another person, and were now single, being divorced or widowed. Being alone was one of the major changes in their lives, which was experienced as both a grievous time as well as a time of relief and freedom. Living in a situation that needed to be changed made them independent and brave.

Although most of the participants appreciated every day, with its joys and sorrows, some of the participants explained their feelings of not looking forward to every day or upcoming events, such as celebrating New Year's Eve, National Day, or birthdays. Activities that they had done for many years, such as writing Christmas cards, going berry-picking, or having big parties, were activities that they might not do anymore. There are things that one lets go as time passes by, as one informant explained.

The participants acknowledged the physical changes in their bodies, having different types of diseases as well as functional disabilities. Although this was the reality, they perceived themselves as being in good health.

\section{Planning for the future}

The participants experienced their life situation as good, as well as acknowledging going through changes and thinking of the future. An important message they expressed was not to be a burden to their children or families. Some of the participants were replanning their houses, making room for another person, so they would not live alone in the house, and which to some extent might make them feel safe. Because the interviewees were living in their own houses or apartments, it was important for them to take into consideration technical equipment for making their everyday life safer and easier. The participants planned for the future by making appointments with the doctor, and this was mentioned as taking care of their health. Public help was anticipated by the interviewees if needed, and was a grounded expectation, even though they did not advertise it. Most of all, to live a physical and social active life was considered to be a vital investment for their health and life situation.

\section{Being generous}

Being a helper, an assistant, and a charitable person

The participants could all be characterized as charitable persons. They were helping their own children as well as grandchildren with practical things, but they were also their support in different life situations. Although they were a support for their own grown children, they chose their own lives trying not to involve themselves too much. Taking care of a sick sister or brother, or other family members, was a part of their lives as well. Being a volunteer in various types of fellowships was appreciated and given priority.

\section{Being appreciated}

The participants found themselves being cared for and loved by their own family members and friends, which was valued. Some of the participants utilized their competence and went to work during the week, and were appreciated by their colleagues. Others were social-minded, writing in newspapers or being engaged in religious or political matters.

\section{Being cheerful}

Participants living their lives facing both their history as well as the unknown future was described through histories of lived lives and characterized as meaningful, good, cheering, worth living, and surrounded by good people who would "golden their days." These experiences also included days with grieving, sorrow, loneliness, and difficulties in finding meaning in life.

\section{Being independent}

\section{Being active and taking one day at a time}

The participants had lived their lives in different places, in Norway as well as abroad. They were active and independent, explaining how they now did what they wanted to do. Most of them drove their own car, traveled, and planned the coming months, as well as taking one day at a time. They were physically active in walking groups, dancing, swimming, and gardening, which also encompassed social activities and fellowship. The participants enjoyed their own company and were engaged in crosswords, Sudoku, read- 
ing, sewing, knitting, collecting stamps, watching TV, etc. Being active and social persons, knowing they had to take initiatives themselves to get involved, they also mentioned people who maybe were lonely and did not take such initiatives for themselves.

The participants were satisfied and enjoyed life. They found their freedom valuable and felt secure, as well as not having any financial problems at the moment.

\section{Interpreted whole}

Strength and a time dimension characterized the meaning of self-care and health for the perception of life situation and identity, as narrated by the group of single-living older individuals in urban areas in southern Norway. The informants were, as older individuals, caring, autonomous, and robust characters who had gone through difficult times in life and in a resilient way moved towards a new future. They valued and were grateful for what they had learned in their lives and could go forward and still experience and explore.

\section{Discussion}

The meaning of self-care and health for the perception of life situation and identity was characterized by the informants' strength and a time dimension. Going through different times in life, they met challenges that constituted a new beginning in their lives. Arendt ${ }^{26}$ expresses how a new beginning always starts through the experiences of life, and is marked by processes that the new beginning interrupts. The new, therefore, appears in the guise of a miracle, where something new is started that cannot be expected. ${ }^{26}$ The old single persons remembered challenging times, such as moving to a new town or a new country, living through physical and mental changes, going through a divorce, or facing the death of a loved one. Although such challenges might be overwhelming, the participants made it through. They seemed to have a strength that led them through these difficult situations and made them act. This strength was not a visible or explicit phenomenon, but rather perceived as an inner strength.

The act that the individuals revealed might be understood as taking an initiative, to begin or set something into motion. The interviewees were not occupied with mortality. Instead, their self-care actions were characterized by natality. ${ }^{26}$ They took initiatives to begin something new and set something into motion that was followed by new actions. These new actions caused changes in the participants' lives as they went through health-related, situational, or developmental transitions. ${ }^{27} \mathrm{~A}$ transition can be characterized as the unstable state between two more stable periods, divided into an ending, a neutral zone, and a new beginning. ${ }^{28}$

Living alone demands self-care actions for managing a complex everyday life in urban areas, which was the situation for the participants in our study. The interviewees were present for the opportunity to act on perceived influences on the body. In addition, either alone or with help from somebody else, they were able to bring about a change in attitude towards their personal lifestyle or life situation. ${ }^{29}$ They actualized their self-care ability in a meaningful way that was important for their perception of their life situation and identity. Findings from other studies ${ }^{8,30,31}$ about self-care in older people point at their ability to act combined with a wish to go on further in life.

The research on self-care and health reveals important knowledge about health promotion, as stated by the Ottawa Charter principle statement, ${ }^{32,33}$ which is based on three elements concerning determinants for health, the process of how people gain control over these determinants, and the ability to lead a full and active life. Self-care should therefore be one of the concepts contributing to the explanation of health in salutogenesis, according to the assets approach presented by Lindström and Eriksson. ${ }^{33}$ They state that salutogenesis contains much more than sense of coherence. It is a much broader concept, focusing on resources, competence, abilities, and assets on different levels. ${ }^{33}$

There are, however, some differences between urban and rural single-living people on the perception of life situation and identity. ${ }^{8}$ Whilst the rural participants searched for comfort in religious belief and were attached to their families, their homes, and rural surroundings, the single urban interviewees in our study gave an impression of having a more material-based security than a spiritual one. Our findings show that older, single, urban-living people in this study were grateful. They lived good lives, as well as finding new meaning in life as time went by. They still expected more of life and wanted to experience and explore. Their health was characterized by expanding consciousness ${ }^{34}$ and human growth or "becoming." 35

There are some interesting findings that might provide further understanding of the meaning of health for the identity of older people. As identity is an ongoing process during the life span, ${ }^{18}$ time, context, and health are influential factors for determining present and future life situations. The findings indicate that we face a new generation of older people who live alone and who have the ability for self-care, strength, and courage. This is most important for society to capture and acknowledge. For the coming decades, society needs 
their knowledge and capabilities to engage in important and necessary work in different fields.

When considering the phenomenological-hermeneutic method used, ${ }^{19}$ there are some issues to address. The interpretation was one of many possible ones, and its relevance to some extent connected to theory about selfcare and health in older people. Through the connection between naïve understanding, structural analysis, and the interpreted whole, the rigor of the study was confirmed. Through this hermeneutic act, we tried to understand the text by following its movement from what it says to what it talks about. Through the mediating role of the structural analysis, both the justification of the objective approach and the rectification of the subjective approach to the text were constituted. The utterance meaning, ${ }^{20} \mathrm{ie}$, what the text says, was not validated against the utterer's meaning, ie, what the informants reported in the interviews. However, the trustworthiness of the analyses is to some degree open to the reader. The findings were obtained in the context of home-living, single-living older people in southern Norway, but it is reasonable to assume that they can be transferred to other similar contexts.

\section{Conclusion}

Self-care is an important asset in a salutogenic view of health. It is significant in the perception of life situation and identity among single urban-living older people in this study, and was characterized by strength, temporality, gratitude, autonomy, and natality. Society needs to acknowledge the strengths and capabilities of older people to a greater extent.

\section{Acknowledgments}

We are grateful to the informants for taking the time to disseminate their experiences. The study was carried out with the financial support of the Research Council of Norway (project number 187985) and the University of Agder.

\section{Disclosure}

The authors report no conflicts of interest in this work.

\section{References}

1. World Health Organization. Why Urban Health Matters. Geneva: WHO; 2010. Available from: http://apps.who.int/iris/bitstream/10665/70230/1/ WHO_WKC_WHD_2010.1_eng.pdf. Accessed January 23, 2013.

2. Rydin Y, Bleahu A, Davies M, et al. Shaping cities for health: complexity and the planning of urban environments in the 21 st century. Lancet. 2012;379(9831):2079-2108.

3. Nummela O, Sulander T, Karisto A, Uutela A. Self-rated health and social capital among aging people across the urban-rural dimension. Int J Behav Med. 2009;16(2):189-194.
4. Sundsli K, Söderhamn U, Espnes GA, Söderhamn O. Ability for selfcare in urban living older people in southern Norway. J Multidiscip Healthc. 2012;5:85-95.

5. Glaeser EL. Triumph of the City. New York: Penguin; 2011.

6. Lau R, Morse CA. Health and wellbeing of older people in AngloAustralian and Italian-Australian communities: a rural-urban comparison. Aust J Rural Health. 2008;16(1):5-11.

7. Gaymu J, Springer S. Living conditions and life satisfaction of older Europeans living alone: a gender and cross-country analysis. Ageing Soc. 2010;30(7):1153-1175.

8. Dale B, Söderhamn U, Söderhamn O. Life situation and identity among single older home-living people: a phenomenological-hermeneutic study. Int J Qual Stud Health Well-being. 2012;7.

9. Tomstad S, Söderhamn U, Espnes O, Söderhamn O. Living alone, receiving help, helplessness, and inactivity are strongly related to risk of undernutrition among older home-dwelling people. Int J Gen Med. 2012;5:231-240.

10. Cheng C. Living alone: the choice and health of older women. J Gerontol Nurs. 2006;32(9):16-25.

11. Foster P, Neville S. Women over the age of 85 years who live alone: a descriptive study. Nurs Prax N Z. 2010;26(1):4-13.

12. Kirkevold M. Facing the challenge of adapting to a life alone in old age: the influence of losses. J Adv Nurs. 2013;69(2):394-402.

13. Orem DE. Nursing: Concepts of Practice. 6th ed. St Louis (MO): Mosby-Year Book; 2001.

14. Söderhamn O. Potential for Self-Care: Assessing and Describing SelfCare Ability among Elderly People [Dissertation]. Linköping, Sweden: Department of Medicine and Care, Division of Nursing Science, Faculty of Health Sciences, Linköpings Universitet; 1998.

15. Nordenfelt L. Dignity in Care for Older People. Chichester, UK: WileyBlackwell; 2009.

16. Taylor C. Sources of the Self. Cambridge, UK: Cambridge University Press; 1989

17. Taylor C. Autentisitetens etikk [The Malaise of Modernity]. Oslo: Cappelen Akademiske Forlag as; 1998.

18. Fillit H, Butler RN. The frailty identity crisis. J Am Geriatr Soc. 2009;57(2):348-352.

19. Lindseth A, Norberg A. A phenomenological hermeneutical method for researching lived experience. Scand J Caring Sci. 2004;18(2): $145-153$.

20. Ricoeur P. Interpretation Theory: Discourse and the Surplus of Meaning. Fort Worth (TX): Texas Christian University Press; 1976.

21. Gustafsson G, Strandberg G. Meanings of staying healthy in a context where others developed burnout - phenomenological-hermeneutic interpretation of healthcare personnel's narratives. Scand J Caring Sci. 2009;23(3):456-464.

22. Nordam A, Torjuul K, Sørlie V. Ethical challenges in the care of older people and risk of being burned out among male nurses. J Clin Nurs. 2005;14(10):1248-1256.

23. Hellzén O, Asplund K. Nurses' narratives about their residents when caring for people with long-term mental illness in municipal group dwellings. Int J Ment Health Nurs. 2006;15(1):60-69.

24. World Medical Association. World Medical Association Declaration of Helsinki: ethical principles for medical research involving human subjects. 2008. Available from: http://www.wma.net/ en/30publications/10policies/b3/index.html. Accessed February 7, 2011.

25. Beauchamp TL, Childress JF. Principles of Biomedical Ethics. 6th ed. New York: Oxford University Press; 2009.

26. Arendt H. The Human Condition. 2nd ed. Chicago: University of Chicago; 1958.

27. Schumacher KL, Meleis AI. Transitions: a central concept in nursing. Image J Nurs Sch. 1994;26(2):119-127.

28. Olsson K, Ek AC. Transition: how a concept has been used in nursing science. Theoria J Nurs Theory. 2002;11(4):4-12.

29. Söderhamn O. Self-care ability in a group of elderly Swedish people: a phenomenological study. J Adv Nurs. 1998;28(4):745-753. 
30. Söderhamn U, Dale B, Söderhamn O. Narrated lived experiences of self-care and health among rural-living older persons with a strong sense of coherence. Psychol Res Behav Manag. 2011;4(1):151-158.

31. Sundsli K, Espnes GA, Söderhamn O. Lived experiences of self-care among older physically active urban-living individuals. Clin Interv Aging. 2013;8:123-130.

32. World Health Organization. The Ottawa Charter for Health Promotion. 1986. Available from: http://www.who.int/healthpromotion/conferences/previous/ottawa/en/index1.html. Accessed March 11, 2013.
33. Lindström B, Eriksson M. The Hitchiker's Guide to Salutogenesis: Salutogenic Pathways to Health Promotion. Helsinki: Folkhälsans Research Center; 2010.

34. Newman MA. Health as Expanding Consciousness. 2nd ed. New York: National League for Nursing Press; 1999.

35. Parse RR. The Human Becoming School of Thought: A Perspective for Nurses and Other Health Professionals. Thousand Oaks (CA): Sage Publications; 1998.

\section{Publish your work in this journal}

Psychology Research and Behavior Management is an international, peerreviewed, open access journal focusing on the science of psychology and its application in behavior management to develop improved outcomes in the clinical, educational, sports and business arenas. Specific topics covered include: Neuroscience, memory \& decision making; Behavior modification \& management; Clinical applications; Business \& sports performance management; Social and developmental studies; Animal studies. The manuscript management system is completely online and includes a quick and fair peer-review system. Visit http://www.dovepress. com/testimonials.php to read real quotes from published authors.

Submit your manuscript here: http://www.dovepress.com/psychology-research-and-behavior-management-journal 